\title{
Jauno amžiaus insultas ir atvira ovalioji anga: diagnoziniai ypatumai ir naujas požiūris ị antrinę profilaktiką (klinikinio atvejo pristatymas ir literatūros apžvalga)
}

\section{Beržanskytè* \\ J. Valaikiene $\dot{e}^{* *}$ \\ D. Jatužis $* *$}

*Vilniaus universiteto

Medicinos fakultetas

**Vilniaus universiteto Medicinos fakultetas, Klinikines medicinos institutas, Neurologijos ir neurochirurgijos klinika; Vilniaus universiteto ligonines Santaros klinikos, Neurologijos centras
Santrauka. Nors nustatyta, kad maždaug kas ketvirtas žmogus turi atvirą ovaliąąa angą (AOA), ši dažniau aptinkama kriptogeninị insultą patyrusių pacientų grupẻje nei tarp sveikų asmenų. Neretai AOA yra atsitiktinis radinys, netureję̨s ịtakos galvos smegenų išemijai, bet kartais tai yra tiesioginis etiologinis insulto veiksnys. İrodyti, kad būtent AOA yra ištikusio insulto priežastis, sudėtinga, todèl dažniausiai AOA lieka tik įtariama insulto priežastimi. Nors per pastaruosius 6 metus pasirodę randomizuoti tyrimai ir metaanalizės, nagrinèję tinkamiausias kriptogeninių insultų su AOA antrinès profilaktikos priemones, pateikia prieštaringas išvadas, naujausių randomizuotų tyrimų ir sisteminių apžvalgų duomenimis, AOA užvėrimas yra pranašesnis už medikamentinę terapiją. Didele problema klinikinėje praktikoje išlieka siekis identifikuoti pacientus, kuriems tokia antrinè insulto profilaktika būtų tinkamiausia, ir nustatyti tikslias indikacijas intervencijai atlikti. Šiame straipsnyje aprašome klinikinị atvejį ir apžvelgiame literatūrą kriptogeninių insultų su AOA diagnostikos ir profilaktikos tema.

Raktažodžiai: atvira ovalioji anga, kriptogeninis insultas, nežinomos kilmės embolinis insultas, paradoksinè embolizacija.

\section{IVADAS}

Atvira ovalioji anga (AOA) nustatoma net $50 \%$ nežinomos etiologijos (kriptogenini) insultą patyrusių pacientų apie du kartus dažniau nei tarp sveikų asmenų [1,2]. Vis dẻlto ne visais kriptogeninių insultų atvejais rasta AOA patvirtina veninès kilmės trombemboliją į smegenis ir dèl to įvykusį smegenų infarktą. Kai kurių autorių duomenimis, $30 \%$ žmonių, patyrusių kriptogeninị insultą ir turinčių AOA, prieširdžių pertvaros defektas yra tik atsitiktinis radinys, neturèjęs įtakos smegenų infarktui [3]. Neretai, nesant kitų galimų insulto etiologinių veiksnių ir nepavykus

\author{
Adresas: \\ Jurgita Valaikiené \\ Vilniaus universiteto ligoninès Santaros klinikos, \\ Neurologijos centras \\ Santariškiu g. 2, LT-08611 Vilnius \\ El.paštas jurgita.valaikiene@santa.lt
}

vizualizuoti trombo atviroje ovaliojoje angoje, AOA taip ir lieka tik numanoma insulto priežastimi. Tokie insultai vadinami kriptogeniniais insultais su AOA [4].

Šiuo metu trūksta tikslių gairių, kaip turètų būti tiriami ir gydomi pacientai, patyrę kriptogeninị insultą su AOA [5]. Vis daugiau randomizuotų tyrimų, sisteminių apžvalgų, metaanalizių bando nustatyti efektyviausią kriptogeninių insultų su AOA antrinės profilaktikos priemonę. Daugejja ịrodymų, kad tinkamiausia antrinės profilaktikos priemonė šiems pacientams yra AOA užvėrimas $[6,7]$.

\section{ATVEJO APRAŠYMAS}

23 m. vyras atvežtas ị Vilniaus universiteto ligoninès Santaros klinikų (VUL SK) prièmimo skyrių dẻl staiga sutrikusios kalbos ir pasilpusių dešiniujų galūnių. Iki tol intensyviai ruošèsi egzaminui, nervinosi, rūkè, sportavo. Pasak ligonio, aprašytas epizodas ištiko pirmą kartą gyvenime,

\footnotetext{
(C) Neurologijos seminarai, 2018. Open Access. This article is distributed under the terms of the Creative Commons Attribution 4.0 International License CC-BY 4.0 (http://creativecommons.org/licenses/by/4.0/), which permits unrestricted use, distribution, and reproduction in any medium, provided you give appropriate credit to the original author(s) and the source, provide a link to the Creative Commons license, and indicate if changes were made.
} 

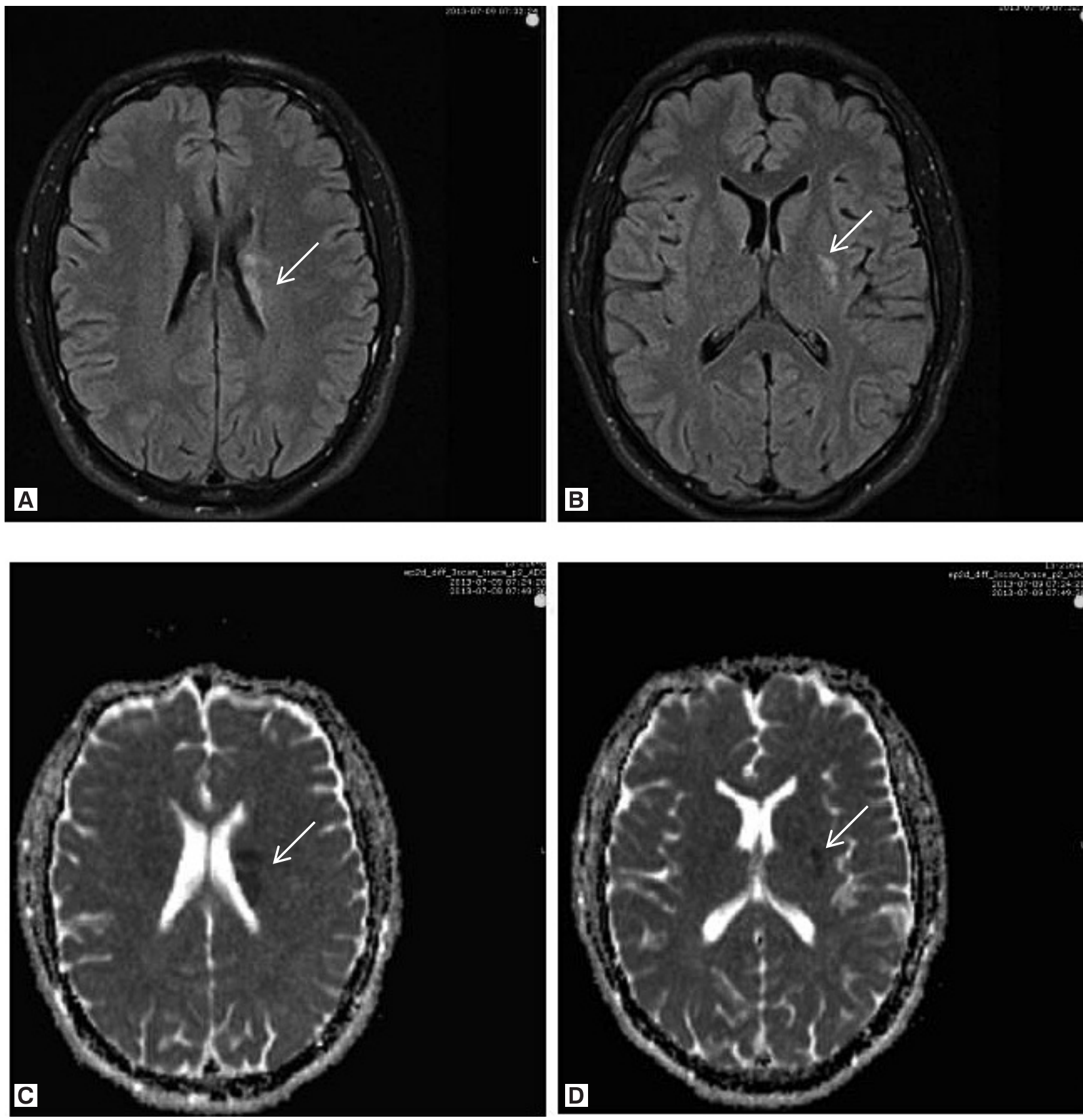

1 pav. Galvos MRT, T2 (A, B) ir DWI (C, D) režimai: išeminiai židiniai kairiosios pusės pamato branduoliuose

Rodyklėmis pažymėti nucleus lentiforme $(\mathrm{B}, \mathrm{D})$ ir nucleus caudatus $(\mathrm{A}, \mathrm{C})$ dorsalinėse dalyse stebimi išemijos židiniai su išreikšta DWI restrikcija.

iki tol buvęs visiškai sveikas. Neurologinės apžiūros metu židininès simptomatikos nenustatyta, dešiniųjų galūnių parezè buvo regresavusi per penkias minutes. Belaukiant atliktų tyrimų atsakymų, pacientas pasiskundè, kad vèl ima silpti dešinioji ranka ir koja. Atliekant pakartotinị neurologinị ištyrimą, nustatyta dešinioji hemiparezė ir hemiataksija. Galvos smegenų kompiuterinės tomografijos (KT) natyviniuose vaizduose pakitimų nediagnozuota. Po kelių minučių neurologiniai simptomai dar kartą išnyko, tačiau greitai vèl atsinaujino. Apžiūrint ligonį, arterinis kraujo spaudimas buvo 140/70 mmHg, širdies susitraukimų dažnis - 67 kartai per min., širdies veikla - ritmiška. Vertinant neurologinę ligonio būklę, konstatuota seklesnè dešinioji nazolabialinė raukšlè, hemihipestezija dešinėje, dešiniụjų galūnių hemiparezè (jèga - 4 balai) ir hemiataksija. Pacientas skubos tvarka hospitalizuotas i VUL SK Neurologijos skyrių. Diferencijuotas ūminis galvos smegenų kraujotakos sutrikimas, arterijų disekacija, demielinizuojantis CNS susirgimas ir neuroinfekcija.

Bendrajame ir biocheminiuose kraujo tyrimuose patologinių pakitimų nenustatyta, D-dimerai ir lipidograma atitiko normą. Atlikus juosmeninę punkciją, smegenu skysčio tyrimai taip pat atitiko normą, IgG ir albumino santykis - normalus, oligokloninès juostos - neišsiskyrè. Ekstrakranijinės ir transkranijinès spalvinès dupleksonografijos metu arterijų stenozei ir disekacijai būdingų požymių 

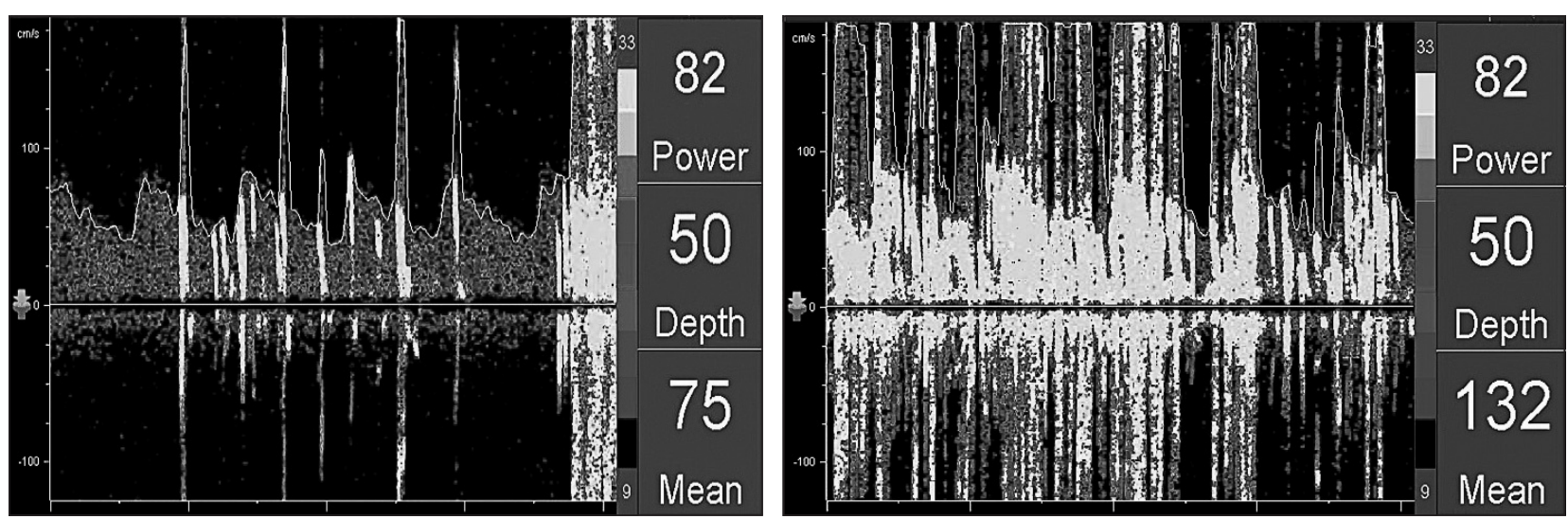

2 pav. Atviros ovaliosios angos diagnostika kontrastinės transkranijinės doplerografijos metodu

Kairẻje - pradejjus švirkšti kontrastinị tirpalą, po 10 sek. vidurinėje smegenų arterijoje pasirodo pirmieji mikroemboliniai signalai; dešinejje - po 13 sek. registruojami ị „užuolaidą“ susiliejantys daugybiniai mikroemboliniai signalai, didelis šuntas.

nenustatyta. Pakartojus galvos smegenų KT angiografiniu režimu, patologijos nediagnozuota. Atlikus magnetinio rezonanso tomografiją (MRT), nustatyti ūminès išemijos židiniai kairiosios pusės pamato branduoliuose (1 pav.). MR angiografiniu režimu slankstelinės arterijos disekacijos nediagnozuota. Smulkūs išeminiai židiniai MRT leido įtarti kardioembolinę jų kilmę.

Elektrokardiogramoje pakitimų nerasta. Transtorakalinès echokardioskopijos (TTE) metu buvo nustatyta gera širdies kairiojo skilvelio inotropija, išmetimo frakcija $55 \%$. Širdies ertmės neišplèstos, mitralinio vožtuvo (MV) bure kiek sustorejjusi. Hemodinamiškai reikšmingų nesandarumų per vožtuvus nestebèta. Patikslinimui atlikus transezofaginę echokardioskopiją (TEE), šuntinių srovių ar kitokios patologijos diagnozuota nebuvo. Atlikus kojų venų dvigubą skenavimą, patologijos nenustatyta. Išliekant paradoksinès embolizacijos įtarimui, nuspręsta atlikti kontrastinę transkranijinę doplerografiją (k-TKD). Tyrimo metu kairiojoje vidurinejje smegenų arterijoje (VSA) registruoti mikroemboliniai signalai (MES), nustatytas šuntinis nuosrūvis iš dešiniosios širdies pusės ị kairiają (trumpiau vadinamas nuosrūviu iš dešinès ị kairę), ypač išryškèjęs Valsavės mėginio metu, - registruoti gausūs, > $25 \mathrm{MES}$, tarpais susiliejantys ị vadinamajji „dušą" (2 pav.). Taigi, $\mathrm{k}$-TKD metodu diagnozuotas didelis šuntas.

Kadangi TEE metodu prieširdžių pertvaros nesandarumas buvo paneigtas, o k-TKD registruotas nuosrūvis iš dešinès ị kairę, buvo įtarta, kad gali vykti ekstrakardinė paradoksinè embolizacija per arterioveninę malformaciją (AVM) plaučiuose. Atlikus krūtinès KT angiografiniu režimu, plaučių AVM ekskliuduota. Nuosrūvio lokalizacijai nustatyti atlikta pakartotinė TEE, jos metu nustatyta AOA. Nesant kitų insulto rizikos veiksnių ir siekiant išvengti pasikartojančių insultų, nuspręsta AOA užverti, atliekant perkateterinę angos korekciją Amplatzer kamštuku. Išmatuotas angos dydis buvo $9 \mathrm{~mm}$. Komplikacijų procedūros metu ir po jos nestebèta. Gydymui skirta klopidogrelio 75 mg 1 kartą per dieną 3 mèn., aspirino 100 mg 1 kartą per dieną 6 mèn.

Kontrolinės k-TKD duomenimis, nuosrūvio iš dešinès ị kairę neregistruota. TTE duomenimis, tarpprieširdinè pertvara - sandari, kamštuko padètis - gera. Praejjus dar 1,5 metų, reikšmingų pokyčių nestebèta.

Dèl ankstyvame amžiuje patirto insulto, rekomenduota hematologo ir genetiko konsultacija, siekiant ligonị ištirti dèl trombofilijos ir paveldimų medžiagų apykaitos sutrikimų. Nustatyta lengvo laipsnio hiperhomocisteinemija, koreguota folinès rūgšties ir B grupès vitaminų preparatais. Ligonis stebėtas neurologų, kardiologų ir genetikų penkerius metus (2013-2018 m.). Kardiovaskuliniai įvykiai nesikartojo.

\section{DIAGNOSTIKA}

Paradoksinės embolizacijos sukeltas insultas dèl prieširdžių pertvaros defektų turi būti ịtariamas pacientams $\leq 60$ metų, atmetus kitas galimas insulto priežastis ir išsiaiškinus, kad, prieš atsirandant židininei neurologinei simptomatikai, asmuo stanginosi: kẻlè ar stūmẻ sunkius daiktus, smarkiai kosėjo [4, 8]. Kai įtariama paradoksinė embolizacija (trombų patekimas ị smegenų kraujagysles iš kojų giliųjų venų arba dubens venų), šuntas iš dešinès į kairę gali būti diagnozuotas atliekant TTE, TEE ir k-TKD. TEE yra jautresnis tyrimo metodas nei TTE, siekiant aptikti embolų širdyje $[4,9,10]$, ir jautresnis bei specifiškesnis tyrimas, siekiant geriau vizualizuoti širdies struktūras, ypač esančias dorsalinėje pusėje (pavyzdžiui, prieširdžiu pertvarą) [11]. Nors šuntas iš dešinės ị kairę gali būti aptiktas ir ramybès metu, tyrimo sėkmè padideja 3-4 kartus [11], jei atliekamas Valsalvės mėginys. K-TKD yra didelio jautrumo ir specifiškumo tyrimas (atitinkamai 92 ir $95 \%$ ) [12], kuris, kai kurių autorių duomenimis, esant pakankamam kauliniam pralaidumui, yra jautresnis nei TEE, siekiant aptikti AOA [11]. Antra vertus, TEE leidžia diferencijuoti nuosrūvio lokalizaciją [8]: patvirtinti intrakardini šuntą dèl širdies pertvaros defektų, o jei nerandama patologinių pokyčių širdyje - ịtarti ekstrakardinị nuosrūvị, pvz., dèl AVM plaučiuose. K-TKD yra neinvazyvus ir nebrangus ultragarsinis tyrimas, todèl rekomenduojamas kaip pirmo pasirinkimo tyrimas stebėti pacientus po AOA užvèrimo $[8,13]$. 
Kadangi manoma, kad trečdaliu atvejų AOA yra atsitiktinis radinys kriptogeninį insultą patyrusių žmonių grupejje, siekiant atskirti nereikšmingą AOA ir reikšmingą AOA insulto patogenezès požiūriu, buvo sukurta RoPE (Risk of Paradoxic Embolism) vertinimo sistema. RoPE balas rodo tikimybę, kad jau ịvykęs insultas arba PSIP buvo susiję su AOA [4, 14, 15]. Kuo didesnis RoPE balas, tuo didesnè tikimybė, kad kriptogeninis insultas ịvyko dėl AOA. Kuo mažesnis RoPE balas, tuo didesnè tikimybe், kad insultas įvyko dèl kardiovaskulinių ir kitų rizikos veiksnių.

Retrospektyviai įvertinę aprašyto ligonio būklę pagal RoPE skalę, gavome 8 balus ( 5 balus - už amžių, 1 balą už hipertenzijos nebuvimą, 1 balą - už diabeto nebuvimą, 1 balą - už ankstesnių insultų ir PSIP nebuvimą). 8 balai atitinka $84 \%$ tikimybę, kad insultas buvo susijęs su AOA, ir $6 \%$ pakartotinio insulto tikimybę per ateinančius dvejus metus [14].

\section{PROFILAKTIKA}

Mohan ir kt. sisteminės apžvalgos ir metaanalizės duomenys parodè, kad pasikartojančio bet kokios kilmės insulto rizika po 1 metų nuo pirmo insulto yra $11,1 \%$ (95\% pasikliautinieji intervalai (PI), 9,0-13,3), o suminè rizika po 5 metu - 26,4 \% (95\% PI, 20,1-32,8), po 10 metų - 39,2 \% (95\% PI, 27,2-51,2) [16]. Nors kriptogeninių insultų su AOA metinè pasikartojimo rizika yra apie $2 \%$, reikia atsižvelgti ị tai, kad kriptogeninị insultą su AOA dažniau patiria jauni žmonès, todẻl svarbu įvertinti suminę riziką per visus paciento gyvenimo metus [17]. Kriptogeninių insultų su AOA antrinei profilaktikai šiuo metu taikoma medikamentinè terapija (antiagregantai ar antikoaguliantai) arba AOA užvėrimas [18].

Iki šiol yra atlikti 5 randomizuoti kontroliuojami tyrimai (CLOSURE-1 2012, PC trial 2013, RESPECT 2013/2017, CLOSE 2017, REDUCE 2017)*, kuriais siekiama išaiškinti efektyviausią pakartotinio insulto prevencijos priemonę kriptogeninį insultą su AOA patyrusiems pacientams. Šių tyrimų rezultatai yra prieštaringi ir turi būti vertinami atsižvelgiant ị tam tikrus veiksnius, galinčius iškreipti rezultatus. CLOSURE I, PC trial ir RESPECT (2013) paneigè AOA užvėrimo pranašumą prieš medikamentinę terapiją, bet RESPECT (2017), CLOSE, REDUCE tyrimų duomenys verčia suabejoti anksčiau atliktų tyrimų rezultatais.

Kadangi insulto su AOA metinė pasikartojimo rizika yra maža, siekiant reikšmingų rezultatų, reikia didelès ti- riamųjų grupès ir ilgesnio nei 5 metai stebejjimo po gydymo laiko [11]. Stebejjimo po gydymo trukmès svarba atsiskleidè atliekant RESPECT tyrimą. Nors 2013 m. (stebejjimo laikas - 2,1 metų) paskelbti RESPECT rezultatai neparodė AOA užvėrimo pranašumo prieš medikamentinę terapiją, 2017 m. RESPECT (stebejjimo laikas - 5,9 metų) tyrimo rezultatai parodè, kad AOA užvėrimas reikšmingai sumažina pasikartojančių insultų dažnị, lyginant su medikamentinę terapiją gaunančiais pacientais. Ne mažiau svarbu atsižvelgti ir į tyrime naudotą AOA užvėrimo prietaisą. Irodyta, kad CLOSURE I tyrime naudotas CardioSEAL-STARFlex kamštukas yra trombogeniškesnis, nei kiti rinkoje esantys AOA užvėrimo prietaisai (pvz., Amplatzer). Po šio prietaiso implantavimo dažniau aptinkama liekamųjų šuntų, padidèja prieširdžių virpėjimo rizika [11, 19]. Visi išvardinti veiksniai didina insulto pasikartojimo riziką intervencijos grupeje ir iškreipia tyrimo rezultatus. PC trial ir RESPECT tyrimuose naudotas Amplatzer prietaisas neturi anksčiau išvardintų neigiamų CardioSEAL-STARFlex savybių. Šiuo metu pacientams, patyrusiems kriptogenini insultą su AOA, pakartotinio insulto prevencijai JAV FDA (Food and Drug Administration) yra patvirtinusi tik Amplatzer prietaisą [20]. Mūsų aprašytu atveju ligoniui AOA uždarymas buvo atliktas būtent Amplatzer kamštuku, ir komplikacijų intervencinès procedūros metu bei po jos neregistruota. Ligonis yra stebimas kardiologų, neurologų ir genetikų, iki šiol kardiovaskulinių įvykių neregistruota.

Didelès reikšmės minètų penkių randomizuotų tyrimų rezultatams turèjo pacientų atrankos kriterijai. Nevienodi atrankos kriterijai ir nevienodas tiriamujų ištyrimas prieš įtraukimą ị tyrimą galèjo iškreipti rezultatus. Pavyzdžiui, CLOSE tyrime buvo atrenkami tik tie pacientai, kurie turèjo didelị nuosrūvị per AOA ir (arba) prieširdžių pertvaros aneurizmą - abu veiksniai didina tikimybę, kad insultas buvo susijęs su AOA, todėl tokiems pacientams AOA užvẻrimas bus akivaizdžiai naudingesnis, nei pacientams, neturintiems minėtų pertvaros defektų. Nepakankamas pacientų ištyrimas prieš įtraukimą ị tyrimą lemia pacientų su žinomos, bet nediagnozuotos kilmès insultais įtraukimą. Pavyzdžiui, CLOSURE I tyrime net $80 \%$ pasikartojusiu insultų galèjo būti paaiškinami prieširdžių virpẻjimu, aortos ateromomis ir kitomis priežastimis, kurios dažniausiai buvo neaptiktos pradinio ištyrimo metu (palyginimui RESPECT tyrime tik $28 \%$ pasikartojusių insultų turèjo alternatyvią priežastį) [20]. Svarbu atsižvelgti ir ị tai, kad AOA galèjo būti užveriama įvairiais FDA patvirtintais prietaisais, skirtais užverti kitus prieširdžių pertvaros defektus, todèl atsirado savęs pasirinkimo šališkumas (selfselection bias). Tai reiškia, kad pacientai, patyrę kriptoge-

${ }^{*}$ CLOSURE-1 - Evaluation of the STARFlex Septal Closure System in Patients With a Stroke and/or Transient Ischemic Attack due to Presumed Paradoxical Embolism Through a Patent Foramen Ovale; PC trial - Clinical Trial Comparing Percutaneous Closure of Patent Foramen Ovale Using the Amplatzer PFO Occluder with Medical Treatment in Patients With Cryptogenic Embolism; RESPECT - Randomized Evaluation of Recurrent Stroke Comparing PFO Closure to Established Current Standard of Care Treatment; CLOSE - Patent Foramen Ovale Closure or Anticoagulants Versus Antiplatelet Therapy to Prevent Stroke Recurrence; Gore-REDUCE - GORE® HELEX® Septal Occluder/GORE® CARDIOFORM Septal Occluder and Antiplatelet Medical Management for Reduction of Recurrent Stroke or Imaging-Confrmed TIA in Patients With Patent Foramen Ovale. 
ninị insultą su AOA ir turintys didesnę insulto pasikartojimo riziką, galejo rinktis iškart užverti AOA ir nedalyvauti randomizuotame tyrime, todèl tyrimuose galimai dalyvavo pacientai su mažesne pakartotinio insulto tikimybe [11].

Rezultatams įtakos galejjo turèti ir skirtingas medikamentinès terapijos standartizavimas tarp tyrimų. CLOSURE I, PC trial ir RESPECT tyrimų metu kontrolinei grupei buvo skiriama antiagregacinė arba antikoaguliacinè terapija, priklausomai nuo tyrèjo pasirinkimo. REDUCE tyrime kontrolinei grupei buvo skiriama tik antiagregacinè terapija, o CLOSE tyrime buvo išskirtos dvi medikamentinès terapijos grupès: antiagregacinè ir antikoaguliacinè.

Profilaktinè medikamentinè terapija po kriptogeninio insulto su AOA vis dar nèra standartizuota. Antikoaguliacinè terapija turi pranašumą prieš kitas prevencijos priemones tais atvejais, kai numanoma kriptogeninio insulto su AOA priežastis yra trombų formavimasis širdyje arba giliosiose kojų venose. 2014 m. AHA/ASA* insulto prevencijos rekomendacijose teigiama, kad antikoaguliaciné terapija turi būti skiriama pacientams, patyrusiems išemini insultą ir turintiems AOA bei embolų šaltinį veninejje kraujotakoje (I klasės, A ịrodymų lygmuo). Tose pačiose rekomendacijose tvirtinama, kad antiagregacinè terapija yra efektyvi antrinès kriptogeninio insulto su AOA profilaktikos priemonè (I klasė, B įrodymų lygmuo), bet vis dar trūksta duomenų, ar antiagregacinè ir antikoaguliacinè terapijos yra vienodai efektyvios (IIb klasė, B įrodymų lygmuo). AOA užvėrimas yra reikšmingas pakartotinių insultų profilaktikai tik tiems pacientams, kuriems AOA yra tikrai asocijuota su išemija smegenyse. Ši ryšį klinikinèje praktikoje įrodyti sunku. 2014 m. rekomendacijose AOA užvėrimas rekomenduojamas tik pacientams, patyrusiems kriptogeninį insultą su AOA, kartu nustačius giliụjų venų trombozę ir atsižvelgiant į pakartotinès giliųų venų trombozès riziką (IIb klasè, C įrodymų lygmuo) [21]. Vis dèlto pasirodžius naujiems randomizuotų tyrimų rezultatams 2017 m. (RESPECT, REDUCE, CLOSE) ir šių tyrimų metaanalizėms, AHA/ASA rekomendacijos turètų būti peržiūrètos ir atnaujintos.

$2018 \mathrm{~m}$. sausio mėnesị pasirodžiusios metaanalizès parodė, kad AOA užvėrimas reikšmingai sumažina insulto pasikartojimo dažnị, lyginant su medikamentine terapija (dažniausiai turint omenyje antiagregacinę terapiją) [20, 22]. Taip pat nustatyta, kad intervencijos grupejje dažniau pasitaiko prieširdžių virpèjimas, kuris gali būti pasikartojančio insulto priežastimi. 56,6 \% pacientų, kuriems buvo užverta AOA ir po procedūros atsirado prieširdžių virpejjimas, širdies ritmo sutrikimas buvo laikinas ir $72 \%$ praejo per 30-45 dienas po intervencijos [22]. Naudojant PC trial, RESPECT, REDUCE ir CLOSE tyrimų duomenis, buvo išvesta Kaplan-Meier kreivė ir nustatyta, kad AOA užvėrimas sumažina išeminio insulto pasikartojimo riziką daugiau nei $80 \%$, lyginant su medikamentinę terapiją gaunančių pacientų grupe [23].

\section{IŠVADOS}

1. Nors transezofaginè echokardioskopija yra specifiškiausias tyrimas atvirai ovaliajai angai diagnozuoti ir laikoma „auksiniu standartu“, pasitaiko ir klaidingai neigiamų diagnozinių atvejų.

2. İtariant paradoksinę embolizaciją insulto atveju, rekomenduojama atlikti kontrastinę transkranijinę doplerografiją šuntui iš dešiniosios širdies ị kairiąą nustatyti.

3. Diagnozavus paradoksinę embolizaciją, reikia nustatyti šuntinio nuosrūvio lokalizaciją (intrakardinė ar ekstrakardinè).

4. Naujausių randomizuotų tyrimų, sisteminių apžvalgų ir metaanalizių duomenimis, jauno amžiaus ligoniams, patyrusiems kriptogeninị insultą, atviros ovaliosios angos užvėrimas yra tinkamesnė antrinės insulto profilaktikos priemonė negu medikamentinès terapijos taikymas.

\section{Literatūra}

1. Webster MW, Smith HJ, Sharpe DN, et al. Patent foramen ovale in young stroke patients. The Lancet 1988; 332: 11-2. https://doi.org/10.1016/S0140-6736(88)92944-3

2. Lechat PH, Mas JL, Lascault G, et al. Prevalence of patent foramen ovale in patients with stroke. New England Journal of Medicine 1988; 318: 1148-52. https://doi.org/10.1056/ NEJM198805053181802

3. Alsheikh-Ali AA, Thaler DE, Kent DM. Patent foramen ovale in cryptogenic stroke: incidental or pathogenic. Stroke 2009; 40: 2349-55. https://doi.org/10.1161/ STROKEAHA.109.547828

4. Melkumova E, Thaler DE. Cryptogenic stroke and patent foramen ovale risk assessment. Interventional Cardiology Clinics 2017; 6: 487-93. https://doi.org/10.1016/ j.iccl.2017.05.005

5. Von Klemperer K, Kmepny A, Pavitt WC, et al. Device closure for patent foramen ovale following cryptogenic stroke: a survey of current practice in the UK. Open Heart 2017; 4: e000636. https://doi.org/10.1136/openhrt-2017-000636

6. Saver JL, Carroll JD, Thaler DE, et al. Long-term outcomes of patent foramen ovale closure or medical therapy after stroke. New England Journal of Medicine 2017; 377: 1022-32. https://doi.org/10.1056/NEJMoa1610057

7. Kitsios GD, Dahabreh IJ, Abu Dabrh AM, et al. Patent foramen ovale closure and medical treatments for secondary stroke prevention: a systematic review of observational and randomized evidence. Stroke 2011; 43: 422-31. https://doi.org/10.1161/STROKEAHA.111.631648

8. Messé SR, Ammash NM. Atrial septal abnormalities (PFO, ASD, and ASA) and risk of cerebral emboli in adults. UpToDate 2017. https://www.uptodate.com/contents/atrialseptal-abnormalities-pfo-asd-and-asa-and-risk-of-cerebralemboli-in-adults

9. De Bruijn SF, Agema WR, Lammers GJ. Transesophageal echocardiography is superior to transthoracic echocardiography in management of patients of any age with transient

*AHA - American Heart Association; ASA - American Stroke Association 
ischemic attack or stroke. Stroke 2006; 37: 2531-4. https://doi.org/10.1161/01.STR.0000241064.46659.69

10. Blum A, Reisner S, Farbstein Y. Transesophageal echocardiography (TEE) vs. transthoracic echocardiography (TTE) in assessing cardio-vascular sources of emboli in patients with acute ischemic stroke. Medical Science Monitor 2004; 10: CR521-3.

11. Tobis J, Sphenoda M. Percutaneous treatment of patent foramen ovale and atrial septal defects. Journal of the American College of Cardiology 2012; 60: 1722-32. https://doi.org/ 10.1016/j.jacc.2012.01.086

12. Homma S, Sacco RL. Patent foramen ovale and stroke. Circulation 2005; 112: 1063-72. https://doi.org/10.1161/ CIRCULATIONAHA.104.524371

13. Komar M, Olszowska M, Przewłocki T, et al. Transcranial doppler ultrasonography should it be the first choice for persistent foramen ovale screening. Cardiovascular Ultrasound 2014; 12: 16. https://doi.org/10.1186/1476-7120-12-16

14. Kent MD, Ruthazer R, Weimar C, et al. An index to identify stroke-related vs incidental patent foramen ovale in cryptogenic stroke. Neurology 2013; 81: 619-25. https://doi.org/10.1212/WNL.0b013e3182a08d59

15. Mončytė M, Ulyte A, Ryliškienė K. Kriptogeninis insultas ir paradoksinès embolijos rizika: RoPE skalè. Neurologijos seminarai 2017; 21: 131-5.

16. Mohan KM, Wolfe CDA, Rudd AG, et al. Risk and cumulative risk of stroke recurrence: a systematic review and metaanalysis. Stroke 2011; 42(5): 1489-94. https://doi.org/ 10.1161/STROKEAHA.110.602615

17. Mas JL, Arquizan C, Lamy C, et al. Recurrent cerebrovascular events associated with patent foramen ovale, atrial septal aneurysm, or both. New England Journal of Medicine 2001; 345: 1740-6. https://doi.org/10.1056/NEJMoa011503

18. Mas JL, Derumeaux G, Amarenco P, et al. CLOSE: Closure of patent foramen ovale, oral anticoagulants or antiplatelet therapy to prevent stroke recurrence: study design. International Journal of Stroke 2016; 11: 724-32. https://doi.org/ $10.1177 / 1747493016643551$

19. Tobis J. Patent foramen ovale and the risk of cryptogenic stroke. Cleveland Clinic Journal of Medicine 2014; 81: 425-6. https://doi.org/10.3949/ccjm.81a.14066

20. Abo-Salem E, Chaitman B, Helmy T, et al. Patent foramen ovale closure versus medical therapy in cases with cryptogenic stroke, meta-analysis of randomized controlled trials. Journal of Neurology 2018; 265(3): 578-85. https://doi.org/10.1007/s00415-018-8750-x

21. Kernan WN, Ovbiagele B, Black HR, et al. Guidelines for the prevention of stroke in patients with stroke and transient ischemic attack: a guideline for healthcare professionals from the American Heart Association/American Stroke Association. Stroke 2014; 45: 2160-236. https://doi.org/ 10.1161/STR.0000000000000024

22. Ntaios G, Papavasileiou V, Sagris D, et al. Closure of patent foramen ovale versus medical therapy in patients with cryptogenic stroke or transient ischemic attack: updated systematic review and meta-analysis. Stroke 2018; 49: 412-8. https://doi.org/10.1161/STROKEAHA.117.020030

23. Piccolo R, Franzone A, Siontis GC, et al. Patent foramen ovale closure vs. medical therapy for recurrent stroke prevention: evolution of treatment effect during follow-up. International Journal of Cardiology 2018; 255: 29-31. https://doi.org/10.1016/j.ijcard.2018.01.001

24. Venturini JM, Retzer EM, Estrada JR, et al. Practical scoring system to select optimally sized devices for percutaneous patent foramen ovale closure. Journal of Structural Heart Disease 2016; 2(5): 217-23. https://doi.org/10.12945/ j.jshd.2016.009.15

\section{Beržanskytė, J. Valaikienė, D. Jatužis}

\section{PATENT FORAMEN OVALE IN YOUNG STROKE PATIENTS: DIAGNOSTIC CHALLENGE AND A NEW APPROACH TO THE SECONDARY PREVENTION (A CASE REPORT AND REVIEW OF LITERATURE)}

\section{Summary}

Patent foramen ovale (PFO) occurs in about $25 \%$ of healthy adults, however, it is significantly more common among patients with cryptogenic stroke. Although PFO might be a direct cause of ischemia, it is often an accidental finding in stroke patients. In most cases, cryptogenic stroke with PFO is just a presumed diagnosis as it is difficult to prove PFO as etiological factor. Randomized trials and meta-analysis have showed controversial results in searching for the most effective prevention of cryptogenic stroke with PFO recurrence in the last six years. Nevertheless, currently available data suggests that PFO closure is superior to medical therapy. Two problems remain in clinical settings: identification of patients who would benefit from PFO closure most and the exact indications for intervention. In this article we present a clinical case and review literature examining diagnostic and secondary prevention of cryptogenic stroke with PFO.

Keywords: patent foramen ovale, cryptogenic stroke, embolic stroke of undetermined source, paradoxical embolization.

Gauta:

20180501
Priimta spaudai: 20180614 